\title{
LA NUEVA RESPUESTA \\ DE LA LITERATURA COLOMBIANA
}

POR

UMBERTO VALVERDE

Desde la consolidación de Gabriel García Márquez con Cien años de soledad hasta su posterior glorificación con el premio Nobel, mucho se ha hablado y escrito sobre el presente y futuro de las nuevas generaciones de escritores colombianos. Sin embargo, la reflexión crítica ha estado ausente de la mayoría de estos análisis. En 1955, Antonio García, en respuesta para un libro de J. M. Alvarez D’Orsonville, decía: «No hay crítica literaria, no hay crítica artística, no hay crítica. Simplemente porque no hay pensamiento crítico. La crítica no nace por generación espontánea, sino como un producto de la madurez intelectual del pensamiento... Si no hemos llegado a la 'edad de la razón', no podemos hablar de pensamiento crítico. Ahora bien: existen comentadores literarios, exegetas y divulgadores.» Las únicas aproximaciones lúcidas han sido hechas por quienes vivimos el compromiso de la escritura. Mientras tanto, los críticos de oficio no responden a sus propias exigencias. Uno de ellos, falsamente connotado, cuando se publicó Cien años de soledad afirmó que se necesitaban cien años para saber si era una gran novela. Otro, con afán publicitario, publicó un folleto, a un mes de la aparición de $E l$ otoño del patriarca, con el único propósito de destruir la novela por presunta desmesura y exagerado barroquismo. A su vez, J. G. Cobo Borda, en «Notas sobre la literatura colombiana», ensayo incluido en el libro Colombia, hoy (Siglo XXI, 1978), hace un salto al vacío desde la producción literaria de José Antonio Osorio Lizarazo, por los años cuarenta, hasta el texto adolescente y débil de Andrés Caicedo, en los setenta, ignorando deliberadamente a todos sus contemporáneos. Cobo Borda, vocero ilustrado de la cultura oficial, ha tratado, con excelente manejo de los medios de información, de convertirse en la única figura sobresaliente de las nuevas generaciones. Su pretensión bordea los límites del ridículo cuando retoma un equivocado 
planteamiento de Octavio Paz para sostener que García Márquez no es más que un popularizador del aporte literario de Gómez de la Serna.

Tanto en lo social como en lo literario, el panorama no parece cambiar. Insuficiencia editorial, escasez de revistas, censura ideológica en los suplementos de los periódicos y una evidente política clasista en la orientación de Colcultura, órgano oficial para el impulso de las artes. A esto se agrega la carrera de entreguismo que ha caracterizado a la gran mayoría de las generaciones intelectuales de nuestro país. Jorge Zalamea y Fernando González, con diferentes actitudes, fueron los únicos de las pasadas generaciones que lograron mantenerse al margen y en réplica al orden instituido. Los integrantes de la revista Mito son hoy día los asesores presidenciales de la cultura. Razones contundentes tenía Nicolás Suescún para sostener, en el prólogo del libro Trece cuentos colombianos (Arca, 1970), que el supuesto papel subversivo adjudicado a Mito por Oscar Collazos era muy relativo. Suescún escribía con certeza: «Mito no representa, pues, un comienzo o atisbo de una nueva actitud... No tuvo una posición política, o, si la tuvo, fue de una cómoda ambigiiedad. El Nadaísmo, por su parte, como movimiento, también entregó sus banderas y su nacimiento iconoclasta. Las posteriores generaciones literarias, cuyo origen de clase corresponde a los sectores medios y bajos, no han transformado radicalmente esta norma establecida. Algunos se aventuraron en el camino del arribismo social; otros se empantanaron en el sectarismo ideológico de izquierda y sólo unos cuantos trataron de asumir con integridad una marginalidad incorrupta y cuestionante.

Esta constante está en íntima relación con un elemento definitivo en la problemática de la literatura colombiana: el respeto por el lenguaje culto y académico, que, naturalmente, plantea una verdadera Torre de Babel entre el lenguaje hablado y el literario. Esta reaccionaria posición, defendida en el siglo pasado por Rufino José Cuervo, se sustenta hoy en los periódicos de la gran burguesía, que siguen alabando a los escritores «castizos». Jorge Ruffinelli, en un breve ensayo sobre García Márquez, sostiene que justamente el autor de Cien años de soledad y Alvaro Cepeda Samudio son los que ponen punto final al lastre idiomático. Con mayor fundamentación y conocimiento, Nicolás Suescún agrega el «libro tardío» de José Félix Fuenmayor. Y anota: «Estos comienzos se ven prolongados ahora por un grupo muy joven de cuentistas de la costa del Pacífico, entre los que descuellan Oscar Collazos y Umberto Valverde, pero que han 1legado a su visión, aún más radical, del lenguaje literario a través de la influencia de escritores latinoamericanos, en particular Julio Cortázar y Cabrera Infante». Dentro de esta óptica es imposible pasar por alto el primer libro de cuentos de Darío Ruiz Gómez, Para que no se olvide su 
nombre (Ed. La Tertulia, 1966). Su autor, en respuesta a un reportaje, nos analiza su opera prima: «Fue deliberadamente una ruptura, una réplica al literaturismo, a una narrativa de frases, al intento de describir un sector de la vida colombiana que no fue arriero, sino bogotano o juglar vallenato.»

Para que la literatura colombiana asumiera su propio destino, abandonando el lenguaje académico y la verborrea de museo, era preciso la aparición de los escritores de provincia, el desenfado de los costeños, la fuerza vital de los antioquenos y la orgía verbal del grupo del Pacífico, que, por razones de raíces culturales, establecía sus fuentes creativas en la línea del Caribe. Ya Pavese lo decía: «Pero lo cierto es que sin provincianos, una literatura carece de nervios.»

Tomás Carrasquilla, el mejor antecedente de la narrativa colombiana, polemizó enérgicamente con los modernistas. Rafael Maya, en Los orígenes del Modernismo en Colombia, nos dice: "Atrincherado en sus riscos y reclamando lo terrígeno sobre lo extranjero, y lo nacional sobre lo erudito y postizo, predicaba realmente en el desierto, pero lo hacía con una pujanza que acaso provenía de su mismo aislamiento. Tuvo que multiplicar las fuerzas para hacerse oír, como quien grita a orillas de una cascada». Carrasquilla le escribía a Max Grillo: «Mi ideal es muy claro. Maximiliano: obra nacional con información moderna; artistas de la casa para la casa. Yo sueño con un 20 de julio literario. ¿Cómo no? Independencia absoluta de todo país extraño... y que vengan pacificadores.» El triunfo posterior de La vorágine, de J. E. Rivera, confirmó las tesis de Carrasquilla, a quien todos habían olvidado. Un crítico burgués como Hernando Téllez, en un reportaje que le hace Abelardo Forero Benavídez, confiesa: «La obra de J. E. Rivera, por ejemplo, fuera de su valor universal, tiene originalidad. No pudo ser escrita sino por un colombiano y constituye un admirable testimonio de lo nuestro, que no puede ser reemplazado por ninguna novela de Kipling. La obra de Valencia, desde el punto de vista universal, podría desaparecer, porque hay otros poetas, europeos, que han dicho lo mismo y lo han expresado con parecida perfección. Valencia seguramente no vio en su vida un camello ni conoció el desierto.» La provincia, los provincianos, le otorgan a la literatura colombiana la auténtica inserción en la vida. Por supuesto, como bien lo decía Baldomero Sanin Cano, «el papanatas nace lo mismo en las Batuecas que en París o en Londres, y a veces en mayor número en estas grandes ciudades, donde la falta de aire y el origen dudoso de los alimentos tienden a deteriorar la especie». El provinciano, con la firmeza de sus raíces culturales, con la información moderna, tal como sucede con Cepeda Samudio, quien regresa a Barranquilla convencido de los aportes 
renovadores de Saroyan, Scott Fitzgerald y la llamada "Generación perdida», para entregarle a la literatura nacional el primer libro de cuentos absolutamente contemporáneo y nuestro. Entre tanto, el intelectual bogotano, nacido o residente, que vive el mito de la capital, el sofisma de la «Atenas sudamericana», es incapaz de reflejar el mundo suburbano, la nueva temática que impone el crecimiento de la ciudad, tal como sucede en ese entonces con la novelística del Plata, por ejemplo con Juan Carlos Onetti y Leopoldo Marechal. Con justa razón, en un editorial de la revista Eco (vocero de la cultura alemana en Bogotá), Ernesto Volkening, un extraño exiliado que fue el primero en valorar la producción literaria de Gabriel García Márquez, se interrogaba: «¿Bogotá hallará a su novelista, será capaz de engendrarlo en sus propias entrañas, y a través de su epopeya se conocerá un día a sí misma?» En los cuarenta, en los comienzos de los cincuenta, Bogotá «tuvo un narrador cuya obra se nutría de su sustancia, su sangre, su tuétano, sin desmerecer, en cuanto atañe al valor literario de algunos nombres más conocidos y de mayor prestigio en el mundo de las letras. Es J. A. Osorio Lizarazo». Ciertamente, después de Osorio Lizarazo, Bogotá no ha podido encontrar a su novelista ni tampoco a su personaje que sea el resultado de sus entrañas y su historia.

Después de la consagración de Gabriel García Márquez, el panorama de la literatura colombiana no se ha reducido ni se ha empobrecido. Es evidente que el desfallecimiento publicitario del boom ha provocado un desajuste en la valoración literaria. García Márquez fue el último en ingresar y terminó siendo la figura globalizante de este fenómeno, que no es tan sencillo de analizar. Angel Rama, con acierto, trató de desmenuzarlo en su texto «El boom en perspectiva». Es incuestionable que un sector de los narradores menores de cuarenta años escogieron el camino aparentemente fácil: «hacerse a la sombra del fabulador reconocido para hacer otras tantas versiones en caricatura de Macondo». Esta alternativa los condena aún más si aceptamos que la obra de Gabriel García Márquez no abre un camino, sino que es la culminación más acabada y perfecta de un proceso. El ciclo que alcanza sus mejores expresiones en Asturias, Rulfo, Roa Bastos, Carpentier, se cierra con El otoño del patriarca.

El grupo más activo de la literatura colombiana, que, mediante una nueva interpretación del realismo y una aproximación profunda al lenguaje popular ha logrado crear una obra trascendente, se puede dividir en dos: los que se fueron y los que se quedaron en el país.

Entre los que se fueron, los que asumieron un voluntario exilio, y los que se quedaron hay una coincidencia sustancial: el amor al país, la fidelidad a sus raíces y, sobre todo, una actitud distante, disidente, crítica y marginal frente al oficialismo cultural, como también al sectarismo iz- 
quierdizante. Armando Romero, integrante del primer grupo, lo dice claramente en un reportaje que nosotros le hicimos: «Me voy porque no me quedaba otra salida, estaba atrapado por el movimiento nadaista y estaba distanciado de mis naturales amigos. Mi única posibilidad de rescate para mí era el exilio; yo me fui para rescatar a Colombia, no para perderla.» A él se agregan otros nombres: Oscar Collazos, Luis Fayad, Rafael Humberto Moreno-Durán y Ricardo Cano Gaviria. Angel Rama se refería a este fenómeno en su interesante pero discutible ensayo "Los contestatarios del poder», por cuanto sobrevalora obras de insignificante valor literario como Años de fuga, de Plinio Apuleyo Mendoza, quien ha ganado la promoción en los últimos tiempos no por sus calidades, sino por la amistad generacional que lo une a Gabriel García Márquez y, sobre todo, por ser un representante del santismo y de la burguesía liberal.

Entre los que nos quedamos (en algunos casos salimos para volver) es preciso citar a Darío Ruiz Gómez, Fernando Cruz Kronfly, Policarpo Varón, Nicolás Suescún, Roberto Burgos Cantor, Rodrigo Parra Sandoval y el autor de estas notas. Todos, a su manera, hemos intentado allanar los terrenos literarios con alcances inusitados: Es así cómo, desde Toque de Diana, de Rafael Humberto Moreno-Durán, pasando por los memorables relatos de La ternura que tengo para yos, de Darío Ruiz Gómez; por la densa estructura poética de Falleba, de Fernando Cruz Kronfly, o el elaborado lenguaje de Lo amador, de Roberto Burgos Cantor, la literatura colombiana ha conocido otros parámetros y otras dimensiones que nunca antes había trajinado. En un balance similar, Fernando Cruz Kronfly establecía con sinceridad los requisitos de sus observaciones: «Se trata, simplemente, de un listado proveniente tanto de la historia como del gusto, y a veces hasta de la simple oportunidad de las cosas. A tal extremo, que a veces, cuando me detengo en este tipo de reflexiones, no dejo de sorprenderme con la de que, en no pocas oportunidades, el cariño por las personas y su propio conocimiento precede el interés por una obra determinada, el cariño por ellas, así como a su comprensión. Aquí la vida, de nuevo, como un modelo de todos modos no impuesto, parece preceder a la escritura y ser su fundamento. La vida como lámpara de alcohol encendida y como canción.»

Este esquema, tan discutible como cualquier otro, nos permite registrar y valorar el trabajo literario de dos escritores contemporáneos entre sí que han sobrevivido a la miseria intelectual de nuestro país desde su peculiar universo. Alvaro Mutis, eterno exiliado en México, y Manuel Mejía Vallejo, distante y crítico desde los riscos y la geografía de su finca, donde afina sus soledades y sus despechos. Alvaro Mutis no sólo es el gran poeta recuperado por las últimas publicaciones, sino el soberbio pro- 
sista de La mansión de Araucaima y el Diario de Lecumberri. Mejía Vallejo, además de su valiosa obra cuentística, nos ha legado una novela de cabecera para todas las nuevas generaciones: Aire de tango.

La diferencia radical entre una literatura postiza y una literatura enraizada en la vida no atraviesa ni se encajona en las equívocas divisiones generacionales. Es así como desde Carrasquilla, pasando por J. E. Rivera, por Gabriel García Márquez, hasta llegar a Burgos Cantor, la diferencia es de actitud ante la vida. Cuando a Witold Gombrowicz le preguntaban sus impresiones sobre los integrantes del grupo Sur en Buenos Aires, respondía: «¿Cuáles eran las posibilidades de comprensión entre esa Argentina intelectual, estetizante y filosofante y yo? A mí lo que me fascinaba del país era lo bajo, a ellos lo alto. A mí me hechizaba la oscuridad de Retiro, a ellos las luces de París.» Asimismo pudiéramos decir que Fernando González, desde Envigado, se preguntó y reflexionó sobre el mundo. Lezama Lima, al salir de su casa, con la compañía de su cigarro, vivió su circunstancia humana sin límites provincianos. El problema es cuando se confunden los valores: en el mediocre mundo universitario de nuestro país, vapuleado por la crisis de la izquierda y por las modas intelectuales, consideran que hablar de Umberto Eco es un «acto de cultura», mientras que hacer mención de Carrasquilla es un «nacionalismo ramplón». Confunden información con cultura. A veces, aprendizaje de memoria y de solapas, con conocimiento. ¿Acaso las alusiones a Parnell, el héroe irlandés, convierten la obra de Joyce en un pasquín patriotero?

Darío Ruiz Gómez, quien hace este último interrogante, también nos reabre el sentido de lo marginal en un hermoso texto del cual extraemos este párrafo: "Lo marginal, lo oculto, lo despreciado - lo pecaminoso casi-, en el sentido cristiano, se identifica, pues, con ese término que tanto se utiliza hoy para señalar precisamente a quienes viven fuera de ese ámbito, a esas ciudadelas: La Habana de Tres tristes tigres, el Bogotá de Osorio Lizarazo, el Buenos Aires miserable de Daniel Moyano. Hay un claroscuro, algo sombrío y despiadado pero vital en el suburbio de Manuel Rojas, de Umberto Valverde, de Vicente Leñero, en los pálidos protagonistas de Julio Ramón Ribeiro. ¿No existe, entonces, una semántica de esas casas? ¿En esos muros donde palpita el recuerdo?»

Las nuevas generaciones de la literatura colombiana surgidas de los sectores sociales medios y bajos soportamos en nuestra infancia el fantasma de la violencia, un acto de barbarie de la clase dirigente sobre el cual se ha tratado de tender un manto de silencio, una matanza de medio millón de personas, la guerra sin cuartel durante las últimas cuatro décadas, la débil democracia-burguesía, que se reconstituyó en un esfuerzo por evitar el desangre y la caída al abismo. Estas generaciones nos abrimos 
paso a pesar de la estructura clasista de la sociedad, alcanzando un reconocimiento por encima del dominio de los medios informativos. A pesar de todo, en un país que no nos ha dado nada, las nuevas generaciones no quisieron, aunque sólo en sus mejores representantes, continuar la tradición entreguista de los intelectuales colombianos. Por el contrario, se ha exaltado, en este sentido, la importancia de un Fernando González. Lastimosamente, en este difícil panorama se agregó el fracaso de los grupos izquierdistas, que nunca pudieron crear una corriente de opinión alterna, en tanto que se interesaron más por repetir un discurso «internacionalista» y vacío que, evidentemente, nunca encontró eco en el pueblo ni en los sectores oprimidos. Sin embargo, no es posible hablar de un país único; como decía Montana Cuéllar, existe un país formal y un país real. Los escritores decidimos vivir y estar al lado del país real: el país de la noche y los orilleros, el país de los desheredados y las prostitutas que se rebuscan su sobrevivencia en las esquinas, el país de los gamines y de quienes, a pesar de todo, decidieron triunfar más allá de las fronteras, el país de la rumba, que no se entrega a la tristeza, sino al placer y al frenesí, el país que no cree en nada sino en sí mismo, en la imaginación y en la lucha cotidiana, en ese inventarse la vida todos los días porque no hay otra salida ni otra posibilidad. 
